Asian J. Med. Biol. Res. 2016, 2 (3), 389-395; doi: 10.3329/ajmbr.v2i3.30108

\author{
Asian Journal of \\ Medical and Biological Research \\ ISSN 2411-4472 (Print) 2412-5571 (Online) \\ www.ebupress.com/journal/ajmbr
}

\title{
Article \\ Tobacco smoking among school adolescents in Northern Sabah
}

$\mathrm{Swe}^{1 *}$, Than Myint ${ }^{1}$ and Mon Mon Yee ${ }^{2}$

${ }^{1}$ Community and Family Medicine Department, Faculty of Medicine and Health Sciences, Unversiti Malaysia Sabah

${ }^{2}$ Reproductive Health Department, Faculty of Medicine and Health Sciences, Unversiti Malaysia Sabah

*Corresponding author: Community and Family Medicine Department, Faculty of Medicine and Health Sciences, Unversiti Malaysia Sabah, Jalan UMS, Kota Kinabalu, 88400, Sabah, Malaysia. Phone: +6 088 320000 Ext: 611505; E-mail: ssdrswe@gmail.com

Received: 09 August 2016/Accepted: 11 September 2016/ Published: 29 September 2016

\begin{abstract}
Tobacco smoking in adolescent age group has become a major public health concern as it is one of the major risk factors for non-communicable diseases leading to burden of adverse health effects in their later life. Those who start smoking tobacco at an early age are more likely to develop nicotine addiction and continue smoking throughout their adulthood. The general objective of the study was to determine the prevalence of tobacco smoking, their initiation and perception towards tobacco smoking among school adolescents in Kudat District, Sabah State, Malaysia. It was a school based cross sectional descriptive study which employed a twostaged stratified random sampling method and used self-administered structured questionnaire for data collection. A total of 257 students aged between 15 to 19 years old from two upper secondary schools participated in the study. This study revealed that (26.6\%) were ever smokers and $(8.6 \%)$ were current smokers. The earliest age of started smoking was 7 years old and 9 years old among male and female ever smokers respectively. Majority of the respondents perceived that smoking was a bad habit which would cause environmental pollution and harmful effects on health. The most common reasons to start smoking among ever smokers were peer pressures, curiosity and experimenting and to relieve the feeling of pressured and stress. Among the current smokers, $86.4 \%$ had ever attempted to quit smoking but they failed to stop smoking because they thought smoking could give feeling pleasure (50\%), relieve their anxiety or craving $(27.3 \%)$ and because of peer pressures $(22.7 \%)$. The findings suggested that although tobacco smoking prevalence among school adolescents in Kudat was comparatively lower than that of national prevalence reported by GYTS, there is still need for early interventions with holistic approach to prevent them from initiation and to help them for cessation of tobacco smoking.
\end{abstract}

Keywords: tobacco smoking; school adolescents; northern Sabah

\section{Introduction}

Tobacco smoking has been one of the greatest public health concerns for the 21 st century in most countries. Tobacco smoking has become a global epidemic which has caused millions of people suffering from chronic disabilities, premature deaths and social economic burden to families and societies. The World Health Organization has estimated that tobacco use (smoking and smokeless) is currently responsible for the death of about six million people across the world each year with many of these deaths occurring prematurely (WHO, 2015).

Recent trends show rising prevalence of tobacco smoking among youth and earlier age of initiation. According to the World Health Organization and other studies, the prevalence of smoking among school-age adolescents was high, especially in developing countries, with estimates ranging from $14 \%$ to $29 \%$ (El Mhamdi et al., 2011).There are 1.2 billion smokers globally, of which more than $50 \%$ are young people. Malaysia alone has 
about 5 million smokers, 20\% of whom are younger than 18 years old (Al-Sadat et al., 2010). Global Youth Tobacco Survey (GYTS), Malaysia, 2009 revealed that among the school children aged between 13 to 15 years, $30.0 \%$ of students were ever cigarette smokers and $18.2 \%$ were current smokers. According to the reports of various studies, prevalence of tobacco smoking among adolescents was 25\% in Malaysia (2006), 25\% in Vietnam (2008) and 78\% in Indonesia (2006)(Al-Sadat et al., 2010).A study done in Kelantan state, Malaysia revealed that $35.9 \%$ of secondary school boys were current smokers (Naing Nyi et al.,2004). Another study done in Kota Tinggi District, Johor reported that smoking prevalence of secondary school students was found to be $29.7 \%$ and smoking was more prevalent among male students (Lim et al., 2006). Also a study carried out in a secondary school Sarawak showed that the prevalence of smoking was $32.8 \%$ with mean age of initiation at $(12.8 \pm 1.9)$ years among secondary school students (Juslina et al., 2011). Therefore, increasing prevalence of adolescence smoking and initiation at early age of life has become a significant public health problem.

Many adult smokers take up the smoking habit during their period of adolescence or as young adults. Much of the severe health consequences of smoking are in adulthood (Rachiotis et al., 2008). The age at initiation of smoking is crucial as those who smoke in adolescence are very likely to smoke as adults. Also most of the adolescents who smoke may also have unhealthy lifestyle clusters such as smoking, alcohol use, engaged in high risk sexual behavior and illicit drug use. So that smoking may be a marker of unwanted harmful adolescents' behaviors (Siziya et al., 2007).

Several factors especially environmental and socio-behavioural factors determined the shifting trend of increased prevalence of tobacco smoking towards younger age group. Adolescents' initiation of smoking can be associated with many risk factors such as curiosity to experiment, peer pressure, family smoking, cultural norms, media influence, advertisement, easy access, weak law enforcement, stress and psychological factors, perception on smoking, insufficient awareness of the smoking hazards, the amount of pocket money they can spend and association with other high-risk behaviours etc. These factors might have synergistic actions to motivate smoking among adolescents. Many young people initiate smoking during their adolescence period, because most of them believe that smoking will boost their social acceptability and image. Adolescents' desire to appear like adults and their need to gain social approval from peers can lead to smoking. Once adolescents have experimented with smoking, almost 50\% continue to smoke and become addicted (Makwana et al., 2007). Peer influence has been found to be the strongest risk factor for smoking among adolescents and identified as a form of social reinforcement (Fuad et al., 2014).

Majority of countries in the world have established smoking control programs to prevent initiation and to promote cessation of tobacco smoking. Adolescence age group must be targeted as the primary focus for strategic implementation to reduce the burden of smoking among them. To support formulation of effective antismoking programs for that adolescence age group who are prone to be habituated to smoking, it is necessary to obtain more information on contributing factors and their perception towards tobacco smoking. Understanding of adolescents' perception on tobacco smoking is a crucial for policy makers and public health managers as it may help in effective planning of tobacco control interventions.

This study was carried out in Kudat area which was located on the northern most part of Sabah, Malaysia, 190 kilometres north of Kota Kinabalu, the state capital. The general objective of the study was to estimate the prevalence, initiation of smoking and perceptions towards tobacco smoking among school adolescents from selected two secondary schools in Kudat. Secondary school students were considered representative of adolescents primarily because schooling was the main activity for targeted age group (15-19 years old) which was a critical period in the development of the smoking habit. The study was conducted with the support of Rural Medicine Research Unit, Faculty of Medicine and Health Sciences, Universiti Malaysia Sabah.

\section{Materials and Methods}

This study was a school based cross sectional descriptive study carried out in two upper secondary schools (SMK Sikuati 1 and SMK Abdul Rahim Kudat) of Kudat District during 2014. Secondary school students attending (Form 4 to Form 6) classes who were supposed to be in the age range of 15 to 19 years old were targeted for the study.

A two-staged stratified random sampling method was used. A detailed list of all the schools providing education for Form 4 to Form 6 grades in Kudat area was obtained and two schools were randomly selected based on its location. Then two classes from each grade (Form 4 to Form 6) of sampled schools were randomly selected. All the students presented in the selected classes on the day of the survey were eligible to participate regardless of their actual ages, religious and ethnicity. Altogether 257 students who gave consents with the permission of the principals from two sampled secondary schools in Kudat participated in the study. 
Self-administered structured questionnaire in Malay version was used for data collection. The validated questionnaire was adopted from previous studies and modified according to the condition and situation of the study area. Questions were translated into Bahasa Malaysia with forward and backward translation and pretested with 30 students from other secondary school who were not involved in the study. Some modifications and refinements were again made to the questionnaire based on the results of the pre-test to enhance clarity. The questionnaire was prepared to be anonymous and to be self-completed by the students who were assured about the confidentiality of collected information.

The questionnaire included four major sections with closed ended questions in Bahasa Malaysia which were about socio-demographic information, knowledge about tobacco smoking, perception towards tobacco smoking and information about smoking practice.

In order to ensure ethical conduct of the research, various measures had been taken by researchers such as obtained prior permission to conduct this study from the heads of the selected upper secondary schools, SMK Sikuati (1) and SMK Abdul Rahim Kudat; obtained verbal informed consent from the parents of the participating adolescents; written consents were obtained from students who were participated in the study; kept anonymity of the students and data security.

Data collection was done by the help of data collectors (research assistants) who were briefed the contents of the questionnaire and process of data collection in details by the researchers one week ahead of the day of data collection.

On the day of data collection, all the students who were eligible to participate in this study were organized in a hall and they were explained about the purpose of the study, expected benefits of the study and the voluntary and anonymous nature of participation in the survey. After the briefing, questionnaires were distributed to all those students who were organized in the hall. The questionnaires were completed in a class time by the students who gave consents to participate in this study. School teachers were not allowed in the hall during the time of questionnaire completion. The researchers were remained present throughout the survey to clarify any queries. Analysis was done only on the completed questionnaires using SPSS version 21 statistical software. Frequencies and proportions were calculated for descriptive statistics.

\section{Operational definitions}

Perception of smoking: a way of regarding, recognition, understanding or interpreting upon tobacco smoking, tobacco hazards and tobacco control measures.

Negative perception upon tobacco smoking: perceived that tobacco smoking is a bad habit, bad behaviour and cause dangerous to individual and public health.

Positive perception upon tobacco smoking: perceived tobacco smoking as positive and believed that smoking is not harmful to health and positive feelings towards tobacco smoking.

Prevalence of smoking: referred to proportion of smokers in secondary school student population.

Ever-smoker: a student who had ever tried smoking tobacco, even once in the past or during his/her lifetime. This student may or may not be a current smoker. In this study ever smoker=ex-smoker + current smoker.

Current smoker: a student who has smoked cigarettes on one or more days in the preceding month (30 days) of the survey.

Ex- smoker: defined as a student who quit smoking more than one year.

Never- smoker: a student who has never experienced in smoking tobacco in his life time.

Quit attempt: current tobacco smokers who tried to quit during the past 6 months.

Knowledge about tobacco smoking: knowledge about health hazards of tobacco smoking, addiction of tobacco smoking and prevention and control activities of tobacco smoking in Malaysia.

\section{Results}

\subsection{Socio-demographic characteristics}

The age range of students participated in the study were between 15 to 19 years old (mean-17.14), constituted mainly 17 years old $(39.3 \%), 18$ years old $(28.4 \%)$ and 16 years old $(26.1 \%)$. Among them $35.8 \%$ were male and $64.2 \%$ were females. Majority of the participants were Rungus (49.4\%) followed by Bajau (24.9\%) in ethnicity. Regarding the religion, 51.4\% were Christian and $48.2 \%$ were Islam. The students participated in this study were from thirty four kampungs which were located within the areas of Kudat town and Sikuati.

\subsection{Smoking status}

Of 257 students, $73.4 \%$ (189) were never smokers, $26.6 \%$ (68) were ever smokers. Among ever smokers 22

( $8.6 \%$ of total) were current smokers and 46 (18\% of total) were ex-smokers. There were more male students 
than female students (Male 70.6\% and Female 29.4\%) among ever smokers. It was also found that 78\% (53) of ever smokers and $95.5 \%$ (21) of current smokers were between 16 and 17 years old.

Among ever smokers, the earliest age of started smoking was 7 years old for male and 9 years old for female students. Majority of ever smokers (79\%) for both gender started their smoking between 12 years to 16 years old of age.

Regarding the types of tobacco products smoked by the current smokers, $77.3 \%$ (17) smoked cigarette, $18.2 \%$ (4) smoked both cheroot and cigarette and only4.5\% (1) smoked hand rolled cheroot.

Table 1. The main reason to initiate smoking among ever smokers.

\begin{tabular}{lll}
\hline Reason & Frequency & Valid Percent \\
\hline Parents / family members smoke & 6 & 8.8 \\
Friends / neighbours smoke & 21 & 30.9 \\
Friends urged & 6 & 8.8 \\
Media influences & 4 & 5.9 \\
Experiment/curiosity & 19 & 27.9 \\
Can get easily & 1 & 1.5 \\
Feeling pressured/depressed \& stress & 10 & 14.7 \\
Other & 1 & 1.5 \\
Total & 68 & 100.0 \\
\hline
\end{tabular}

Table 2. Attempted to quit smoking among current smokers during the past six months.

\begin{tabular}{llll}
\hline Gender & \multicolumn{2}{c}{ Attempted to quit smoking } & Total \\
\cline { 2 - 3 } & Yes & No & \\
\hline Male & $15(68.2 \%)$ & $3(13.6 \%)$ & $4(81.8 \%)$ \\
Female & $4(18.2 \%)$ & $0(0 \%)$ & $4(18.2 \%)$ \\
Total & $19(86.4 \%)$ & $3(13.6 \%)$ & $22(100 \%)$ \\
\hline
\end{tabular}

Table 3. Knowledge level of tobacco smoking hazards among respondents.

\begin{tabular}{ll}
\hline Level of knowledge & Frequency (\%) \\
\hline Good & $178(69.2 \%)$ \\
Fair & $78(30.4 \%)$ \\
Poor & $1(0.4 \%)$ \\
Total & $257(100 \%)$ \\
\hline
\end{tabular}

Table 4. Perception towards tobacco smoking among respondents.

\begin{tabular}{lll}
\hline Statement & Agree & Disagree \\
\hline Smoking is a bad habit & $96.9 \%$ & $3.1 \%$ \\
Youth smoking is a problem in Malaysia & $98.8 \%$ & $1.2 \%$ \\
Tobacco smoking can cause harmful effects on health & $92.8 \%$ & $7.2 \%$ \\
Second hand smoke would get adverse effect of smoking & $77.4 \%$ & $22.6 \%$ \\
Smoking can give rise to air pollution and give harmful effect to environment & $89.5 \%$ & $10.5 \%$ \\
Started smoking among youth is due to easily accessible and affordable & $74.5 \%$ & $25.5 \%$ \\
Tobacco smoking is just wasting our pocket money & $96.7 \%$ & $3.3 \%$ \\
Smoking can cause negative social and personal impacts on youth & $82.1 \%$ & $17.9 \%$ \\
Youth should not have a right to smoke if he or she wishes & $83.7 \%$ & $16.3 \%$ \\
Quitting of smoking is difficult due to its addictive effect of nicotine & $92.6 \%$ & $7.4 \%$ \\
Quitting of smoking in youth is difficult mainly due to peer pressures & $73.2 \%$ & $26.8 \%$ \\
Media has influence on youth smoking & $98.3 \%$ & $1.7 \%$ \\
Prohibition of tobacco advertisement can reduce the number of smokers & $70.4 \%$ & $29.6 \%$ \\
Prohibition of tobacco smoking in public places should be encouraged & $79.0 \%$ & $21 \%$ \\
Smoking under 18 years should be banned by law & $94.5 \%$ & $5.5 \%$ \\
\hline
\end{tabular}




\subsection{Initiation of smoking}

The main reasons of initiation of smoking among ever smokers were found to be due to friends/neighbours smoke $(30.9 \%)$, curiosity and experimenting (27.9\%) and want to relieve from pressured, stressful feeling $(14.7 \%)$ (Table 1).

\subsection{Attempted to quit smoking}

Majority of current smokers (86.4\%) had ever attempted to quit smoking during the past six months. But even though they tried, they failed and continued smoking for some reasons (Table 2). The main reason for which they failed to quit and continued to smoke were because of feeling pleasure and relaxation (50\%), they perceived smoking could reduce their anxiety or craving $(27.3 \%)$ and peer pressures $(22.7 \%)$.

\subsection{Knowledge of tobacco smoking hazards}

Total score given to assess knowledge level of tobacco smoking was 22. Regarding the level of knowledge it was considered that poor knowledge was scored 7 and below, fair knowledge was from 8 to 15 and good level was 16 and above. Mean score obtained by the students was 16.48 .

Among all the respondents, 69.2\% (178) and 30.4\% (78) were found to have good level and fair level of knowledge about health hazards of tobacco respectively (Table 3).This study also revealed that $73.5 \%$ of ever smokers had awareness of harmful effects of tobacco smoking by the time they started to smoke and the remaining $(26.5 \%)$ did not have awareness about tobacco smoking hazards.

\subsection{Perception towards tobacco smoking}

Majority of the students participated in the study reported negatively perceived on tobacco smoking. They did agree that smoking was a bad habit which would cause adverse effects on health. The detail responses were shown in (Table 4).

\section{Discussion}

This study revealed that out of 257 studied secondary school adolescents, $26.6 \%$ were ever smokers and $8.6 \%$ were current smokers. Smoking prevalence of secondary school adolescents in Kudat district area was seemed to be lower than that of the GYTS Malaysia, 2009 results (ever smokers 30\% and the current smokers 18.2\%). Also this prevalence was found to be relatively lower than those in Kelantan state (35.92\%) and Kota Tinggi District, Johor (29.7\%).Smoking distribution among ever smokers by gender has shown more male students (70.6\%) smoked tobacco than female students (29.4\%) like the results of other studies.

The age range of $78 \%$ of ever smokers and $95.5 \%$ of current smokers were between 16 to 17 years age group. Among ever smokers, 79\% was found to be initiated their smoking between 12 and 16 years old. The earliest age of started smoking was reported that 7 years old for male and 9 years old for female students which indicated that the school children were likely to start smoking at their very early age of life. The peer pressures (30.9\%), curiosity and experimenting (27.9\%) and to relieve feeling depressed or pressured (14.7\%) were found to be the main causes to initiate smoking among school adolescents. The peer influence and experiment to get new experience were seemed to be the major influencing factors to start their smoking.

The study also informed that $86.4 \%$ of current smokers ever tried to quit smoking during the past six months of the study but they had failed due to the facts that they felt pleasure and relaxation with smoking (50\%), they relieved their anxiety or craving by smoking (27.3\%) and their friends, parents and neighbours smoked (22.7\%). The study also revealed that among the ever smokers, $73.5 \%$ were aware the harmful effects of tobacco smoking but the remaining (26.4\%) had lack of awareness of tobacco smoking hazards by the time they started to smoke. The findings suggested that health education emphasis on tobacco smoking must be carried out on regular basis mainly in primary and secondary schools for providing the students with greater awareness and understanding of health risks and pertinent issues related to tobacco smoking.

Regarding the level of knowledge about health hazards of tobacco smoking, among 257 students who were participated in the study, $69.2 \%$ were at good level, $30.4 \%$ at fair level and only $0.4 \%$ had poor level of knowledge which indicated that majority of the students were found to be at satisfactory level of awareness of adverse effects on tobacco smoking. It can be assumed that though harmful effects of tobacco smoking are well known, many young people start smoking during their adolescence might probably due to some reasons like peer pressures as peers can lead to smoking, desire to gain social approval from peers, want to have new experience as stimulated by media and want to appear as adults etc.

According to the results of perception on tobacco smoking, among all participants, $96.9 \%$ perceived that smoking is a bad habit and $98.8 \%$ seemed to realise that tobacco smoking has been a problem among 
adolescents in Malaysia. Also $92.8 \%$ of the participants were aware that tobacco smoking can be harmful to health and it can give rise to adverse effects on health and $89.5 \%$ did agree that smoking is an environmental hazard which can cause air pollution. But $22.6 \%$ of participants were not aware that passive smokers (second hand smoke) also have the risks of tobacco smoking.

The findings of the study showed that $74.5 \%$ of participants did agree that started smoking at younger age was due to easily affordable because of cheap cost of cigarettes and easily accessible to buy cigarettes at shops. Majority of the students (96.7\%) thought tobacco smoking was just wasting their pocket money. The 92.6\% of the participants perceived that addictive effect of nicotine is one of the barriers to quit tobacco smoking but $73.2 \%$ thought peer pressures could be the main barrier for young age group. Also $98.3 \%$ of the participants believed that media has been one of the influencing factors on tobacco smoking among young age group and media should give more effort on anti-tobacco control programmes.

The results also revealed that $82.1 \%$ of the participants were found to be aware of the facts that people would look down on those who smoked at public place and youth could not be impressed by smoking as well. Most of the students (83.7\%) did not recommend that youth should have a right to smoke if he or she wishes. The participants did agree that prohibition of tobacco advertisement could reduce the prevalence of tobacco smoking (70.4\%), tobacco smoking in public places should be prohibited (79\%) and smoking under 18 years old should be banned by law $(94.5 \%)$.

\section{Conclusions}

The findings of the study suggested that intervention efforts are essential to prevent initiation of smoking from youth especially school adolescents and to equip them with better awareness and understanding of tobacco smoking hazards and issues. Contents highlighting the adverse effects of tobacco smoking should be included in the formal educational program so that school children can be convinced with the harmfulness of tobacco smoking. Strategic plans to protect adolescents from being exposed to tobacco smoking of other people like parents, relatives, peers, neighbours should be developed to prevent them from experimenting with tobacco. Effective and efficient interventions against tobacco smoking should also be implemented in the community with the support of various types of media as the findings of this study informed that peer influences seemed to be a major influencing factor for taking up or experimenting smoking. Intervention approaches should not only be confined to secondary schools but also to extend to their residential places so that influences in their homes' environmentas well as social environment which contribute to tobacco smoking would be tackled. It is crucial that the family, relatives, peers, community, schools and local authorities need to actively take part their roles in anti-smoking campaigns amongst young age group. Counselling with the parents to control the influence of tobacco smoking on their children should be encouraged. Since schools could be a chancy environment for taking up or experimenting smoking for the adolescents, more large scale of analytical studies are necessary to determine the extent of social and environmental factors influencing on school adolescents' smoking behaviour.

\section{Acknowledgements}

The authors would like to express heartiest gratitude to Rural Medicine Research Unit, Faculty of Medicine and Health Sciences, Universiti Malaysia Sabah for the financial support to carry out this research. Our special thanks and deepest appreciation to the Head Masters of the secondary schools of Kudat district, SMK Sikuati 1 and SMK Abdul Rahim for their kind permissions to carry out this study at their schools. Also expand our heartfelt thanks to all the teachers from those schools who had given such attention and time to help us out in the process of data collection. Special thanks are extended to all students participated in the study and put their efforts in completing the questionnaires for this research. Finally, our special gratitude goes to all those who had directly or indirectly involved and provided us the possibility in completing this study and report writing.

\section{Conflict of interest}

None to declare.

\section{References}

Al-Sadat N, AY Misau, Z Zarihah, D Maznah and TT Su, 2010. Adolescent tobacco use and health in Southeast Asia. Asia-Pac. J. Public Health, 22:175S-180S.

Faud Maher D.Fuad, Ahmad Fairuz, MNA Balsam, Nawwar Ghassan Ibraheem and A Ayob, 2014. Smoking among Malay Upper Secondary School Students in Shah Alam, Selangor.Int. J. Collab. Res. Intern. Med. Public Health, 6:23-28.

Juslina O, M Leelavath, O Khairani and T Iryani, 2011. Prevalence of smoking among secondary school 
students in sarawak. Malays Fam Physician, 6:66-67.

Lim KH, NM Amal, K Hanjeet, MY Mashod, WM Wan Rozita, MG Sumarni and NO Hadzrik, 2006. Prevalence and factors related to smoking among secondary school students in Kota Tinggi District, Johor, Malaysia. Trop. Biomed., 23:75-84

Makwana N, VR Shah and SBYadav, 2007. A Study on Prevalence of Smoking and Tobacco Chewing among Adolescents in rural areas of Jamnagar District, Guja- rat State. JMSR, 1:47-50.

El Mhamdi S, G Wolfcarius-Khiari, S Mhalla, KB Salem and SM Soltani, 2011. Prevalence and predictors of smoking among adolescent schoolchildren in Monastir, Tunisia. EMHJ, 17:523-528.

Naing Nyi N, Z Ahmad, R Musa, F Hamid Abdul, H Ghazali and M Bakar Abu, 2004. Factors related to smoking habits of male adolescents. Tob. Induc. Dis., 2:133-140.

Rachiotis G, AS Muula, E Rudatsikira, S Siziya, A Kyrlesi, K Gourgoulianis and C Hadjichristodoulou, 2008. Factors associated with adolescent cigarette smoking in Greece: results from a cross sectional study (GYTS Study). BMC public health, 8:313.

Siziya S, E Rudatsikira, AS Muula and PRT Ntata, 2007. Predictors of cigarette smoking among adolescents in rural Zambia: results from a cross sectional study from Chongwe district. Rural Remote Health, 7:728.

WHO, 2015. WHO global report on trends in prevalence of tobacco smoking 2015. WHO Library Cataloguingin-Publication Data, 1-359. 